\title{
Cyclosporine Lipid Nanocapsules as Thermoresponsive Gel for Dry Eye Management: Promising Corneal Mucoadhesion, Biodistribution and Preclinical Efficacy in Rabbits
}

\author{
Lubna M. Eldesouky ${ }^{1}{ }^{\circledR}$, Riham M. El-Moslemany ${ }^{1, *}$, Alyaa A. Ramadan ${ }^{1}$, Mahmoud H. Morsi ${ }^{2}$ \\ and Nawal M. Khalafallah ${ }^{1}$ \\ 1 Department of Pharmaceutics, Faculty of Pharmacy, Alexandria University, Alexandria 21523, Egypt; \\ lubna.eldesouky@alexu.edu.eg (L.M.E.); alyaa.ramadan@alexu.edu.eg (A.A.R.); \\ nawal.khalafallah@alexu.edu.eg (N.M.K.) \\ 2 Department of Ophthalmology, Faculty of Medicine, Alexandria University, Alexandria 21523, Egypt; \\ morsimahmoud@yahoo.de \\ * Correspondence: riham.elmoslemany@alexu.edu.eg; Tel.: +2-01006020405
}

Citation: Eldesouky, L.M.; El-Moslemany, R.M.; Ramadan, A.A.; Morsi, M.H.; Khalafallah, N.M. Cyclosporine Lipid Nanocapsules as Thermoresponsive Gel for Dry Eye Management: Promising Corneal Mucoadhesion, Biodistribution and Preclinical Efficacy in Rabbits. Pharmaceutics 2021, 13, 360. https:// doi.org/10.3390/pharmaceutics13030360

Academic Editor: Aleksander F. Sikorski

Received: 5 February 2021

Accepted: 5 March 2021

Published: 9 March 2021

Publisher's Note: MDPI stays neutral with regard to jurisdictional claims in published maps and institutional affiliations.

Copyright: (c) 2021 by the authors. Licensee MDPI, Basel, Switzerland. This article is an open access article distributed under the terms and conditions of the Creative Commons Attribution (CC BY) license (https:/ / creativecommons.org/licenses/by/ $4.0 /)$.
Abstract: An ophthalmic cyclosporine (CsA) formulation based on Lipid nanocapsules (LNC) was developed for dry eye management, aiming to provide targeting to ocular tissues with long-term drug levels and maximum tolerability. CsA-LNC were of small particle size (41.9 $\pm 4.0 \mathrm{~nm})$, narrow size distribution (PdI $\leq 0.1$ ), and high entrapment efficiency (above $98 \%$ ). Chitosan $(C)$ was added to impart positive charge. CsA-LNC were prepared as in-situ gels using poloxamer 407 (P). Ex vivo mucoadhesive strength was evaluated using bovine cornea, while in vivo corneal biodistribution (using fluorescent DiI), efficacy in dry eye using Schirmer tear test (STT), and ocular irritation using Draize test were studied in rabbits compared to marketed ophthalmic CsA nanoemulsion (CsA-NE) and CsA in castor oil. LNC incorporation in in-situ gels resulted in an increase in mucoadhesion, and stronger fluorescence in corneal layers seen by confocal microscopy, compared to the other tested formulations. Rate of recovery (days required to restore corneal baseline hydration level) assessed over 10 days, showed that CsA-LNC formulations produced complete recovery by day 7 comparable to CsA-NE. No Ocular irritation was observed by visual and histopathological examination. Based on data generated, CsA-LNC-CP in-situ gel proved to be a promising effective nonirritant CsA ophthalmic formulation for dry eye management.

Keywords: cylclosporine A; lipid nanocapsules; thermoresponsive gel; corneal delivery; dry eye

\section{Introduction}

The present study was motivated by the need for effective affordable cyclosporine A (CsA) eye drops for the management of Dry Eye disease (DED). According to the Tear Film and Ocular surface Society Second Dry Eye Workshop (TFOS DEWS II) [1], prevalence of DED ranged between $5-50 \%$ reaching up to $75 \%$ in some populations, higher in Asian than in Caucasian populations. Linear increase in prevalence is evident with increase in age, with women more prone to DED than men [2]. If untreated, patients with dry eye may suffer potentially blinding infections, such as bacterial keratitis [3]. CsA is the anti-inflammatory of choice for treatment of DED, particularly severe cases; it is suitable for long term use without adverse effects commonly associated with corticosteroids [4]. CsA is currently available in Egypt for delivery to the eye as $0.05 \%$ oily solution (using castor or olive oil) in which CsA powder is dissolved with the help of ethanol (10\% of the final formulation) or in which the contents of Neoral ${ }^{\circledR}$ CsA oral soft gelatin capsules are dissolved) [4-7]. Another alternative, unaffordable to many, is Restasis ${ }^{\circledR}$, a marketed nanoemulsion eye drops formulation [8]. Both oily solution and nanoemulsion have received conflicting reports on patient tolerability, ocular bioavailability, and side effects such as itching, redness, and burning sensation $[4,8]$. 
This study aimed to develop an aqueous ophthalmic, patient friendly, CsA formulation. Among preformulation issues considered was CsA poor solubility and permeability. Although hydrophobic, CsA is a class IV drug in the BCS [9], showing low solubility [10,11] and low permeability [12], due in part, to its large molecular size [11,13]. A nano-system capable of effectively encapsulating CsA, holding it in solution state and facilitating its uptake in the cornea was targeted. Several nanodelivery systems for ocular delivery of CsA providing prolonged release have been discussed [4]. Lipid nanocapsules (LNCs), relatively new biomimetic nanovectors for drug and gene delivery $[14,15]$ were considered a good choice in the present study. They are prepared using a solvent-free method [16] and consist of an oily core surrounded by a tensioactive rigid membrane of lecithin and pegylated surfactant, providing a hybrid structure between polymeric nanocapsules and liposomes. LNCs show good colloidal properties with a size range $20-100 \mathrm{~nm}$ and a narrow range of dispersity [17], considered added benefit in ocular delivery [14-18]. Moreover, LNC dispersions are physically stable maintaining their structural integrity for long periods of time [16].

A further advantage of LNCs is their ability to encapsulate hydrophilic drugs such as fondaparinux [19] and doxorubicin [20], lipophilic drugs such as paclitaxel [21], praziquantel [22], and itraconazole [23], and amphiphilic drugs such as amiodarone [24].

LNCs were previously reported to enhance drug delivery through oral $[19,23]$, parenteral [20], and topical [23] routes. Recently, LNCs were investigated for ocular use [25,26]. One of these studies showed that blank LNCs had no effect on viability of human corneal epithelial (HCE) cells, and did not cause corneal damage, opacity, conjunctival chemosis, conjunctival redness, vitreous haze, or retinal damage following subconjunctival injection of drug-loaded LNCs in rabbits [25].

Another preformulation issue tackled is the ease with which most aqueous ophthalmic preparations are washed out by tears. Several strategies are known to improve precorneal retention, among them in situ gels. They have the advantage of both liquids and gels; providing easy instillation as well as an improvement of precorneal retention once they attain gel state in physiological conditions [27,28].

Poloxamers are triblock copolymers widely used as non-ionic surfactants and solubilizers [29]. They are generally recognized as safe (GRAS) excipients and have been investigated for oral, rectal, ophthalmic, nasal, and vaginal use [30]. Poloxamer 407 has the lowest toxicity and low critical gelation concentration among the poloxamers and has been extensively studied for ophthalmic use [29]. Thermosensitivity of poloxamer gels is concentration-dependent; higher concentrations result in faster gelling at lower temperatures [31]. Poloxamer in situ gel exhibits pseudoplastic shear thinning flow resulting in good spreading over the cornea surface during blinking (representing periods of high shear stress), however, still being retained on the surface [32]. Poloxamer 407, widely used in ophthalmic products [29] was selected in the present study to develop in situ gels. To the best of our knowledge, LNC in situ gels were prepared for the first time in the present study.

Chitosan is considered a cationic agent of choice for ocular formulations; it is a biocompatible and biodegradable linear polysaccharide with several free amino groups imparting a positive charge capable of interacting with negatively charged cornea surface mucin. There is some evidence that chitosan might enhance cornea uptake of drug molecules $[4,33]$. It is thought to act as a permeation enhancer due to its mucoadhesive properties. It binds to the epithelial cells membrane and the positive charge results opening the ZO-1 tight junction [34]. Chitosan was added to the LNC in situ gel formulation to enhance corneal mucoadhesion aiming to further improve gel resistance to washing out.

The objective of the present study was to develop a thermoresponsive mucoadhesive ophthalmic gel containing CsA encapsulated in LNCs and to characterize the developed formulation in vitro to assess pharmaceutical attributes, ex vivo using excised bovine cornea to assess mucoadhesion, and in vivo in rabbits to assess biodistribution, irritation potential, and efficacy in a dry eye model. 


\section{Materials and Methods}

\subsection{Formulation Preparation}

All stated concentrations refer to concentrations in the final formulations.

\subsubsection{Preparation of Blank and CsA-Loaded LNCs}

LNCs were prepared using the phase inversion and temperature cycling method [16]. Propylene glycol dicaprylate (Labrafac ${ }^{\circledR}$ lipophile WL 1349, Gattefossé S.A., Saint-Priest, France), macrogol 15 hydroxystearate (Kolliphor HS $15^{\circledR}$, formerly Solutol, BASF, Ludwigshafen, Germany), deionized water (1:1:3 by weight), $\mathrm{NaCl} 0.44 \% w / v$ and phosphatidylcholine (Lipoid S100 0.75\% w/v, Lipoïd GMBH, Ludwigshafen, Germany) were heated under magnetic stirring to $85{ }^{\circ} \mathrm{C}$ followed by cooling to $60{ }^{\circ} \mathrm{C}$. Heating/cooling was repeated for 3 cycles at a rate of $4{ }^{\circ} \mathrm{C}$ change $/ \mathrm{min}$.

In the last cycle, quenching was induced by a 3.5-fold dilution using cold deionized water $\left(2{ }^{\circ} \mathrm{C}\right)$ added at the phase inversion temperature (PIT) around $75^{\circ} \mathrm{C}$, detected visually when the mixture appeared translucent. The dispersion was left under slow magnetic stirring for $5 \mathrm{~min}$, filtered through a $0.45 \mu \mathrm{m}$ syringe millipore filter, and kept at $4{ }^{\circ} \mathrm{C}$ until further characterization.

For CsA-loaded LNCs (CsA, Dalian Launcher Fine Chemical Co., Ltd., Dalian, China), $10-50 \mathrm{mg}$ CsA $/ 10 \mathrm{~mL}$ formulation were added with LNC ingredients from the beginning.

\subsubsection{Preparation of Poloxamer In Situ Gels ( $\left.P_{\text {in situ gels }}\right)$}

Concentrations of Poloxamer 407 (P) (BASF, Germany) ranging from 17.5 to $25 \% w / w$ were prepared by dissolving in cold deionised water $\left(4-8^{\circ} \mathrm{C}\right)$ with continuous stirring for $3 \mathrm{~h}$ and refrigerated overnight $[35,36]$.

\subsubsection{Preparation of Chitosan/Poloxamer In Situ Gel ( $\left.\mathrm{CP}_{\text {in situ gel }}\right)$}

Chitosan (C), (molecular weight 100,000-300,000, Acros organics, part of Thermo Fisher Scientific, Geel Belgium) $0.5 \% w / v$ was dispersed in $1 \% v / v$ acetic acid solution and stirred overnight. Poloxamer (17.5 to $25 \% w / w$ ) was dissolved in the chitosan solution, stirred for $3 \mathrm{~h}$, and refrigerated overnight [37].

For CsA-containing in situ gels, CsA was dissolved in the cold in situ gel ( $P_{\text {in situ gel }}$ and $\left.\mathrm{CP}_{\text {in-situ gel }}\right)$, resulting in a clear solution.

\subsubsection{Preparation of LNC In-Situ Gels}

Compatibility between poloxamer and LNC ingredients was first investigated by FTIR (Supplementary Material).

For gel preparation, poloxamer $(17.5$ to $25 \% w / w)$ was dispersed in cold LNC dispersion and refrigerated overnight. Quenching volume used in LNC preparation was decreased to accommodate volume increase due to added poloxamer.

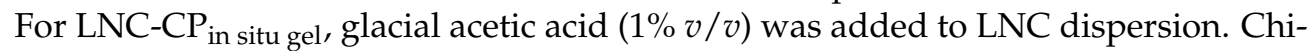
tosan powder $(0.5 \% w / v)$ was dispersed in the acidified LNCs and stirred overnight. Poloxamer was added to the LNC-chitosan mixture.

In all in situ gel formulations prepared, final CsA concentration was $0.1 \% w / v$. Selected formulations with CsA concentration $0.05 \% w / v$ were also prepared for in vivo testing.

\subsection{In Vitro Characterization}

\subsubsection{Characterization of In-Situ Gels}

Determination of Gelling Temperature

Gelling temperature was measured on $2 \mathrm{~mL}$ samples using the inverted tube method [35]. The samples were heated from $20^{\circ} \mathrm{C}$ to $70^{\circ} \mathrm{C}$ at a rate of $1{ }^{\circ} \mathrm{C} / \mathrm{min}$. 
Determination of Gelling Time

Time in seconds for sol-gel transition in blank in situ gels using $100 \mu \mathrm{L}$ samples was determined using an aluminum pan placed on a hot plate maintained at $37^{\circ} \mathrm{C}$. Gelation time was recorded when the sol ceased to flow when pan was tilted $90^{\circ}$ [35].

Viscosity Measurement

Viscosity was measured using cone and plate viscometer (Brookfield, DV2T, USA) at $10 \mathrm{rpm}$ using spindle 40 for $5 \mathrm{~min}$., at $25^{\circ} \mathrm{C}$ and at $37^{\circ} \mathrm{C}$. Profiles were plotted at different shear rates $(1,5,10,50 \mathrm{rpm})$ at $37^{\circ} \mathrm{C}$ using the Rheocalc $\mathrm{T}$ software. Both upwards and downwards curves relating shear stress to shear rate were generated to detect possible thixotropic behavior.

\subsubsection{Colloidal Characterization of LNC as Dispersion and in In-Situ Gel}

Mean particle size and polydispersity index (PdI) of LNCs were determined by photon correlation spectroscopy (PCS), and the zeta potential ( $\zeta$-potential) was measured by Laser Doppler Velocimetry (LDV) using a Malvern Zetasizer (Nano ZS Series DTS 1060, Malvern Instruments Ltd., Malvern, UK) at a fixed angle $173^{\circ}$ at $25^{\circ} \mathrm{C}$ using a $4 \mathrm{~mW}$ He-Ne laser at $633 \mathrm{~nm}$. Samples were diluted 1:20 v/v with filtered deionized water prior to measurements. Data were processed using the Zetasizer software (version 7.02). The same procedure was applied for sizing LNC gels. Three samples per formulation were measured in triplicate $(n=9)$.

\subsubsection{Microscopical Examination}

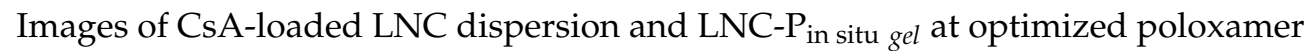
concentration were taken by transmission electron microscopy (TEM, Jeol, JEM-100 CX Electron Microscope, Tokyo, Japan) preceded by negative staining for $30 \mathrm{~s}$ of 4 -fold diluted samples with deionized water using $2 \% w / v$ aqueous uranyl acetate solution. Photographs were taken at 30-40 K X magnification power at $80 \mathrm{kV}$.

\subsection{Entrapment Efficiency (\%EE) and Drug Loading}

Percent EE was determined by measuring free (un-entrapped) CsA separated from LNC dispersion using an ultrafiltration/centrifugation technique for $30 \mathrm{~min}$ at $3663 \times g$ at $25^{\circ} \mathrm{C}$ (SartoriusTM Vivaspin 6, MWCO 100,000) [38]. For in situ gels (LNC-P in situ gel $_{\text {and }}$ LNC-CP in situ gel), 1:4 dilution with deionized water was done prior to ultracentrifugation. Entrapped CsA was calculated from the difference between total CsA concentration $(\mathrm{Ct})$ and free concentration (Cf), divided by $\mathrm{Ct}$.

To determine $\mathrm{Ct}$, LNC dispersion $(100 \mu \mathrm{L})$ was diluted with methanol (up to $2 \mathrm{~mL}$ ), sonicated for $20 \mathrm{~s}$ and CsA assayed by a validated HPLC method (Supplementary Material).

Drug payload was calculated by dividing Ct by dry weights of the LNC ingredients. The effect of initial amount of CsA on EE and on LNC properties was also determined.

\subsection{Stability Testing of LNC Dispersion and LNC In-Situ Gels}

Formulations were refrigerated for 6 months at $4{ }^{\circ} \mathrm{C}$. Particle size, PdI, and $\zeta$-potential were assessed monthly during the first three months and after 6 months by Malvern Zeta sizer. Changes in \%EE were also monitored.

\subsection{Ex Vivo Mucoadhesion Study}

Mucoadhesion force was measured using the modified physical balance method [39]. Bovine eyeballs were obtained from a local slaughterhouse and used on the same day of ablation. Cornea preparation followed the reported procedure [40]. Method details are provided in Supplementary Material. 


\subsection{In Vivo Studies in Rabbits}

\subsubsection{Ethics Statement}

Animal studies were conducted at the Animal Experimentation Facility, Faculty of Pharmacy Alexandria University, Egypt, in accordance with Principles of Laboratory Animal Care and institutional Guidelines for ethical conduct in use of animals in research. Efforts were made to minimize animal suffering. The study protocols were approved by the institutional Ethics Committee.

\subsubsection{Animals}

Male New Zealand colored rabbits weighing $1.2-1.5 \mathrm{~kg}$ and free from any visible ocular damage were selected. Rabbits were provided with food and water in a temperaturecontrolled room $\left(25^{\circ} \mathrm{C}\right)$.

\subsubsection{Corneal Biodistribution Study}

DiI (1,1-Dioctadecyl-3,3,3,3 tetramethyl indocarbocyanine perchlorate, Sigma-Aldrich, USA) was used for fluorescent labeling. Labeling method is provided in Supplementary Material.

A total of 4 rabbits were used. Fifty microliters of fluorescent -labeled blank formulations were instilled in lower conjunctival sac (DiI-LNC dispersion, DiI-LNC-CP in situ gel, DiI-castor oil and DiI solution as control). Rabbits were sacrificed $3 \mathrm{~h}$ post administration and the eyes were enucleated and stored in $10 \% v / v$ formalin. Histological sections, $5 \mu \mathrm{m}$ thick, were prepared for laser scanning confocal microscopy (detailed in Supplementary Material).

\subsubsection{Efficacy in the Dry Eye Rabbit Model}

Schirmer Tear test (STT) [41] was used. Eighteen rabbits were randomly divided into 6 equal groups. CsA-LNC-CP in situ gel $(0.05 \%$ and $0.1 \% w / v)$ was compared with marketed CsA-NE and with CsA solution in castor oil (0.05\%). Positive (untreated) and negative (receiving normal saline) control groups were included.

Using Schirmer tear test strips, tear production was monitored over a total of 10 days. Induction of dry eye (starting on day 0 ) was done using $50 \mu \mathrm{L}$ of $1 \%$ atropine sulphate (AS) eye drops, three times daily instillation in both eyes for 3 days [42]. This was followed by daily treatment using the CsA formulations $(50 \mu \mathrm{L})$ from day 4 to 10 , half an hour after instillation of $1 \%$ AS. Tear production was assessed on day 0 (baseline) and on day 3 following AS administration for 3 days, as well as on days 5, 7, and 10. The STT strip (Eye Care Products Delhi, India) was placed inside the margin of the lower eyelid for two min and the level of strip wetting was noted. The height of the strip wetted by the tears was recorded in millimeters.

\subsubsection{Ocular Irritation Assessment in Rabbits}

Nine rabbits were divided into three equal groups given either $50 \mu \mathrm{L}$ of CsA-LNCs$\mathrm{CP}_{\text {in situ gel }}(0.1 \%)$ or CsA-NE or CsA eye drops in castor oil. Self-control method was adopted; right eye was treated, and left eye was given the same volume of normal saline solution. Rabbits were treated twice daily for 14 days. Visual inspection of the eye took place over 14 days for any signs of ocular reaction (redness, discharge, swelling, iris hyperemia, and corneal lesions or opacity) and continued for three days after stopping treatment [43]. Draize scoring system was applied.

Rabbits were euthanized with an intravenous air injection and eyeballs were enucleated for histopathological examination using a light microscope. Enucleated eyeballs were fixed in $10 \%$ formalin. Five-micrometer-thick histological sections were stained with hematoxylin and eosin. 


\subsection{Statistics}

Data comparison was performed by one-way ANOVA followed by pairwise comparisons (Tukey test) using SPSS 20.0; (SPSS Inc., Chicago, IL, USA). Significant differences were considered at $p \leq 0.05$.

\section{Results and Discussion}

LNCs were successfully prepared using the phase inversion method [16] with no modification and resulted in LNC with good quality attributes.

\subsection{LNC Characteristics}

Mean particle size of blank LNCs was $39.75 \pm 1.48 \mathrm{~nm}$, PdI 0.04, and zeta potential $-3.2 \pm 2.1 \mathrm{mV}$; the negative charge is most likely due to the presence of small proportion of hydrolyzed surfactants [44]. Loading $10 \mathrm{mg}$ CsA $(0.1 \% w / v)$ resulted in minimum change in colloidal properties (size $41.9 \pm 4.0 \mathrm{~nm}$ ) and zeta potential $-4.0 \pm 1.50 \mathrm{mV}$. PdI value remained less than 0.1 for $10-50 \mathrm{mg}$ initial CsA. CsA-loaded LNCs were spherical in shape and monodispersed (Figure 1a,b).

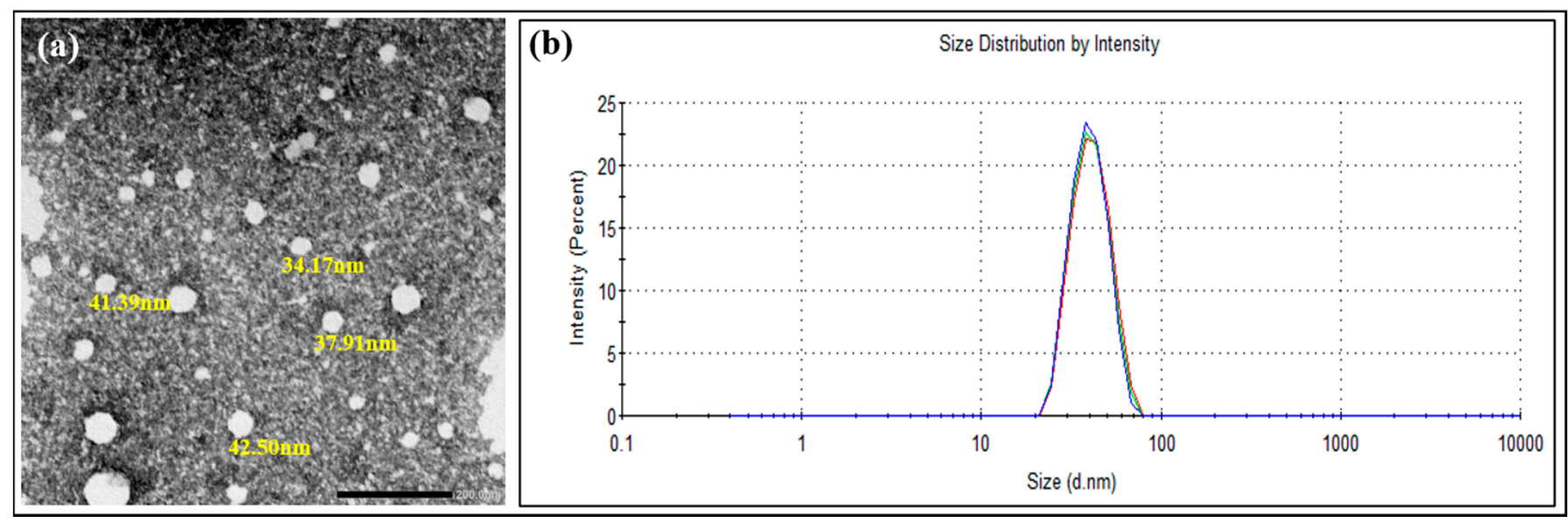

Figure 1. (a) TEM image of CsA-loaded lipid nanocapsules (LNCs) $\times 30,000$. The scale bar represents $200 \mathrm{~nm}$. (b) Size distribution by intensity curve of CsA-loaded LNC dispersion.

\subsection{HPLC Data}

CsA was assayed by HPLC; peak areas were linear over concentration range $0.5-25 \mu \mathrm{g} / \mathrm{mL}$, $r^{2} \geq 0.99$ (Supplementary Material, Figure S1). Heating the column to $80{ }^{\circ} \mathrm{C}$ sharpened the peak [45]. Limits for detection and quantification were $0.132 \mu \mathrm{g} / \mathrm{mL}$ and $0.438 \mu \mathrm{g} / \mathrm{mL}$, respectively. Inter- and intra-day precision for standard CsA solutions were $9.45 \pm 3.54 \%$ and $1.24 \pm 0.16 \%$, respectively, as an indication of precision, with inter- and intra-day mean percent recovery of $99.13 \%$ and $98.97 \%$, respectively, as an indication of accuracy.

\subsection{CsA Loading and Entrapment Efficiency (EE)}

At initial CsA amount (10 to $50 \mathrm{mg} / 10 \mathrm{~mL}$ dispersion), determined total CsA (free and entrapped) ranged from $9.6 \pm 0.6$ to $47.6 \pm 4.2 \mathrm{mg}$. EE was constant and above $98 \%$ (calculated from determined total and free CsA), and CsA payload ranged from $0.83 \%$ to $4.18 \%$. Beyond $50 \mathrm{mg}$ initial CsA, signs of drug precipitation were evident.

High entrapment of CsA is mostly due to its incorporation in the oily core of LNCs due to its lipophilic nature $(\log \mathrm{P}=3)$. Similar results have been previously reported with lipophilic drugs in LNCs, such as paclitaxel [21], ropivacaine [46], and praziquantel [22]. CsA concentration targeted in the final formulation was $0.1 \%(10 \mathrm{mg} / 10 \mathrm{~mL})$. Higher CsA concentrations (up to $50 \mathrm{mg} / \mathrm{mL}$ ) successfully loaded in LNCs could prove useful in veterinary ophthalmic CsA products requiring higher CsA concentrations. 


\subsection{Gel Characteristics ( $P_{\text {In Situ gel }}$ and LNC-P In Situ gel)}

Gelling data (Table 1) identified optimum $P$ concentration for ocular $P_{\text {in situ gel }}$ and assessed effects of chitosan and LNCs on gelling temperature, gelling time, and viscosity. The optimum in situ gels identified (shaded in Table 1) were selected for further ex vivo and in vivo assessment.

Table 1. Gelling properties and viscosity of blank $P_{\text {in situ gels }}$ and LNC-P $P_{\text {in situ gels. }}$

\begin{tabular}{|c|c|c|c|c|c|c|}
\hline In Situ Gel & $\begin{array}{c}\text { Poloxamer\% } \\
w / w\end{array}$ & $\begin{array}{c}\text { Chitosan } \% \\
w / v\end{array}$ & $\begin{array}{c}\text { Gelling } \\
\text { Temperature, }{ }^{\circ} \mathrm{C}\end{array}$ & $\begin{array}{l}\text { Gelling Time, } \\
\text { (Seconds) }\end{array}$ & $\begin{array}{l}\text { Viscosity at } 25^{\circ} \mathrm{C} \\
\text { (Centipoise) }\end{array}$ & $\begin{array}{c}\text { Viscosity at } 37^{\circ} \mathrm{C} \\
\text { (Centipoise) }\end{array}$ \\
\hline \multirow{4}{*}{$P_{\text {in situ gel }}$} & 17.5 & - & $63.8 \pm 0.59$ & $>120$ & $1.74 \pm 1.5$ & $3.49 \pm 4$ \\
\hline & 20 & - & $46.4 \pm 1.65$ & $>120$ & $6.97 \pm 1.5$ & $16.57 \pm 4$ \\
\hline & 22.5 & - & $39.9 \pm 0.75$ & $71.8 \mathrm{~s} \pm 7.5$ & $13.08 \pm 2.62$ & $174.4 \pm 41$ \\
\hline & 25 & - & $34.8 \pm 0.32$ & $15.77 \mathrm{~s} \pm 1.28$ & $31.39 \pm 5.23$ & $1143 \pm 199$ \\
\hline \multirow{4}{*}{$\mathrm{CP}_{\text {in situ gel }}$} & 17.5 & 0.5 & $\mathrm{a}$ & $>120$ & $33.13 \pm 4$ & $32.3 \pm 4$ \\
\hline & 20 & 0.5 & $42.6 \pm 0.50$ & $>120$ & $42.7 \pm 4$ & $43.6 \pm 14.4$ \\
\hline & 22.5 & 0.5 & $36.9 \pm 0.29$ & $51.74 \mathrm{~s} \pm 1.6$ & $66.27 \pm 4$ & $235.5 \pm 50.9$ \\
\hline & 25 & 0.5 & $31.8 \pm 0.91$ & $12.65 \mathrm{~s} \pm 0.55$ & $101.2 \pm 8.4$ & $1252.2 \pm 163$ \\
\hline \multirow{4}{*}{ LNC-P $_{\text {in situ gel }}$} & 17.5 & - & $39.5 \pm 0.2$ & $57.6 \mathrm{~s} \pm 6.37$ & $34.88 \pm 4$ & $240.7 \pm 66.7$ \\
\hline & 20 & - & $34.0 \pm 0.4$ & $11.5 \mathrm{~s} \pm 0.6$ & $94.17 \pm 7.4$ & $1087.1 \pm 254.9$ \\
\hline & 22.5 & - & $32.6 \pm 0.1$ & $8.9 \mathrm{~s} \pm 0.93$ & $266.8 \pm 4.5$ & $1787.7 \pm 200$ \\
\hline & 25 & - & $30.0 \pm 1.35$ & $\mathrm{~b}$ & $1021.8 \pm 216.7$ & c \\
\hline \multirow{4}{*}{$\mathrm{LNC}-\mathrm{CP}_{\text {in situ gel }}$} & 17.5 & 0.5 & $45.1 \pm 0.56$ & $46.5 \mathrm{~s} \pm 4.3$ & $66.27 \pm 3$ & $375.4 \pm 25.1$ \\
\hline & 20 & 0.5 & $34.2 \pm 0.47$ & $11.4 \mathrm{~s} \pm 0.26$ & $136.9 \pm 15.9$ & $1315.5 \pm 129.4$ \\
\hline & 22.5 & 0.5 & $28.9 \pm 1.15$ & $6.1 \mathrm{~s} \pm 0.75$ & $342.7 \pm 32.77$ & $2002.3 \pm 96.7$ \\
\hline & 25 & 0.5 & $24.6 \pm 1.0$ & $\mathrm{~b}$ & $1598.5 \pm 103.9$ & c \\
\hline
\end{tabular}

a Beyond $70{ }^{\circ} \mathrm{C} ;{ }^{b}$ Gel at room temperature; ${ }^{\mathrm{c}}$ Out of range of viscosities.

Increasing $\mathrm{P}$ concentration resulted in a decrease in gelling temperatures $(p<0.005)$. Similarly, addition of Chitosan $(0.5 \%)$, resulted in a significant decrease in gelling temperature (at P 20 to $25 \%$ ) (Table 1). P $(25 \% w / w)$ formed gel at $34.8 \pm 0.32{ }^{\circ} \mathrm{C}$, consistent with reported data stating that $25 \% \mathrm{w} / \mathrm{w}$ Pluronics are required to form a stiff gel upon ocular administration $[47,48]$.

LNC- $P_{\text {in situ gel }}$ showed lower gelling temperature than $P_{\text {in situ gel }}$ at all $P$ concentrations (Table 1); increased P solution viscosity by LNCs nano-state probably contributed. Similarly, solid lipid nanoparticles in P gel, demonstrated decreased gelling temperature and gelling time as well as increased gel viscosity and mechanical strength [49]. A similar observation was reported by Nie et al. [36], where the addition of liposomes to P resulted in a decrease in gelling temperature.

Rheograms constructed showed shear thinning behavior of the in situ gels (Figure 2a), which is considered optimal for ocular administration; ocular shear rate ranges from $0.03 \mathrm{~s}^{-1}$ during inter-blinking periods to $4500-28500 \mathrm{~s}^{-1}$ during blinking. The shear thinning property will allow good distribution of the formulation over the ocular surface during blinking. In addition, during inter-blinking periods, high viscosity will maintain prolonged contact between gel and corneal surface $[31,32,50]$. In situ gels showed thixotropic behavior (Figure 2b), with the downwards curves exhibiting lower shear stress compared to corresponding points on the upwards curves. The inclusion of LNCs did not apparently affect the observed hysteresis loops. 

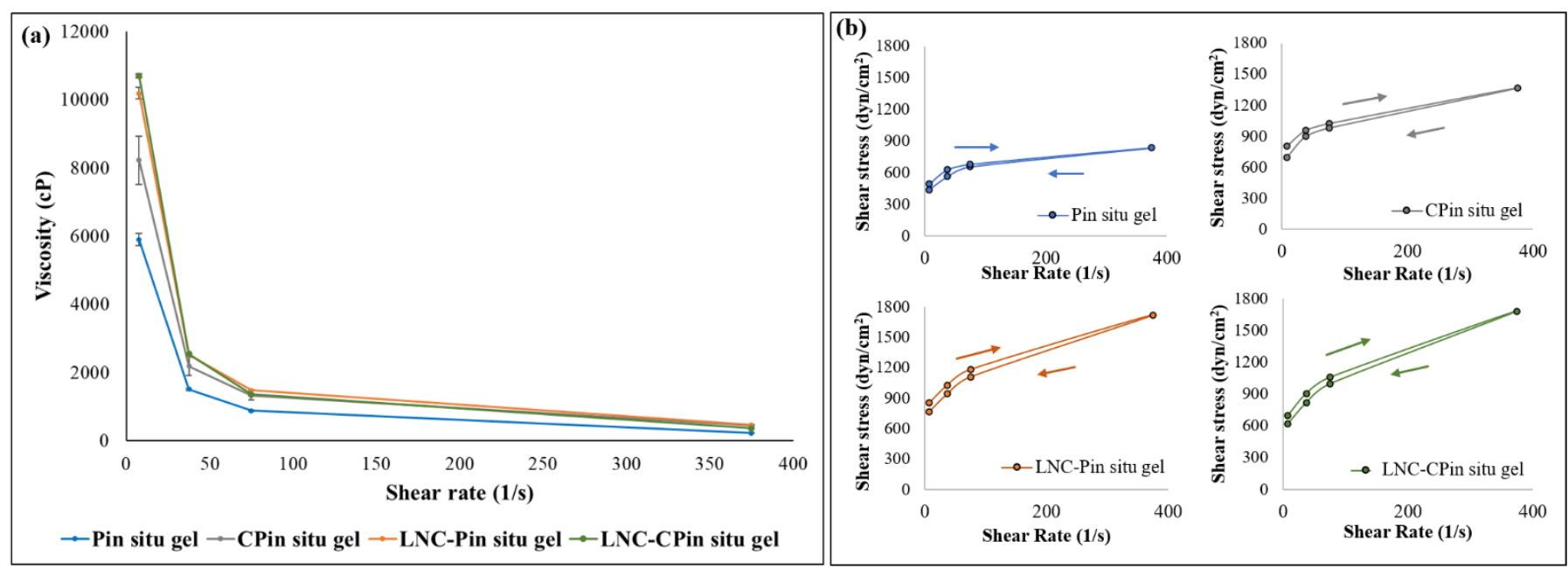

Figure 2. (a) Rheogram of blank in situ gels at physiologic temperature. (b) Thixotropic behavior of in situ gels.

\subsection{Effect of Poloxamer on LNC Colloidal Properties}

Size enlargement was evident for both LNC and LNC-Chitosan after addition of $\mathrm{P}$ (Figure 3a). TEM image of LNC-P confirmed increase in size (Figure 3b).

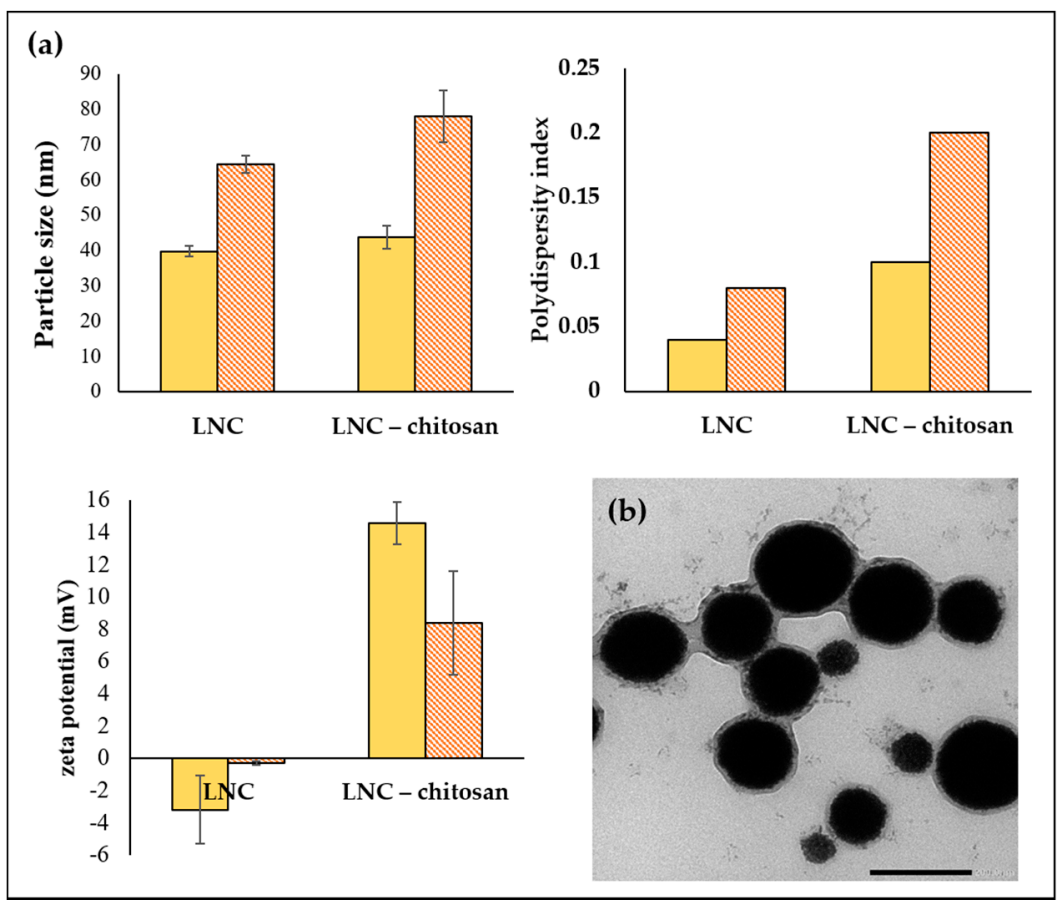

Figure 3. Effect of poloxamer on (a) blank LNC and blank LNC-chitosan colloidal properties and (b) on morphology of blank LNC. A poloxamer sheath surrounding the LNCs can be seen in Figure 3b at 40,000 magnification.

When comparing each in situ gel with its respective dispersion there is a significantly higher PdI $(p<0.01)$ (Figure 3a), which remained, however, less than 0.2 indicating monodispersity of LNC-P $\mathrm{P}_{\text {in situ gel }}$ and LNC-CP in situ gel. This increase in PdI could be attributed to the adsorption of $\mathrm{P}$ on the LNCs' surface, not to particle agglomerates as previously suggested by Hao et al. for SLNs [51]. Addition of poloxamer to LNC formulations (both LNC and LNC-C) showed a significant decrease in surface charge when comparing the in situ gel with its respective dispersion $(p<0.05)$ (Figure 3a). This could also be due to the formation of the poloxamer sheath surrounding the LNCs, masking the surface 
charge. Nanostructured lipid carriers in $20 \% \mathrm{P}$ also showed a marked decrease in zeta potential [52].

\subsection{Compatibility of Poloxamer with LNC Ingredients}

No incompatibility was detected by FTIR between P and LNC ingredients (Supplementary material, Figures S2-S4). Poloxamer has been previously used as an in situ gelling agent incorporating nanoparticles. Nie et al. [36] prepared liposomes containing paclitaxel dispersed in $18 \%$ P thermoreversible gel. Ketoconazole loaded nanoparticles were also dispersed in 16\% [50]. Desai et al. [53] prepared polyisobutylcyanoacrylate nanocapsules dispersed in $25 \% \mathrm{P}$ with $5 \%$ methylcellulose.

\subsection{Storage Stability Data at $4{ }^{\circ} \mathrm{C}$ of $C s A-L N C_{\text {dispersion }}$ and $L N C_{\text {in situ gel }}$}

Particle size, PdI, $\zeta$ - potential, and entrapment efficiency were monitored over six months (Figure 4). Particle size of freshly prepared CsA-LNC dispersion showed marginal increase from $42.2 \pm 0.2$ to $44.9 \pm 1.4$; corresponding data for $\mathrm{LNC}^{\mathrm{P}} \mathrm{P}$ in situ gel and LNC-CP in situ gel were $64.96 \pm 3.1$, and increased to $85.9 \pm 2.6$ and $79.1 \pm 8.1$ to $115.45 \pm 15.0$, respectively ( $p<0.05$, in case of in situ gels). Changes were evident in the first two months and tended to stabilize beyond. A possible explanation for apparent size enlargement in case of in situ gels is progressive hydration of poloxamer sheath surrounding LNCs, while LNC size remained relatively unaffected, as seen with $\mathrm{LNC}_{\text {dispersion. }}$

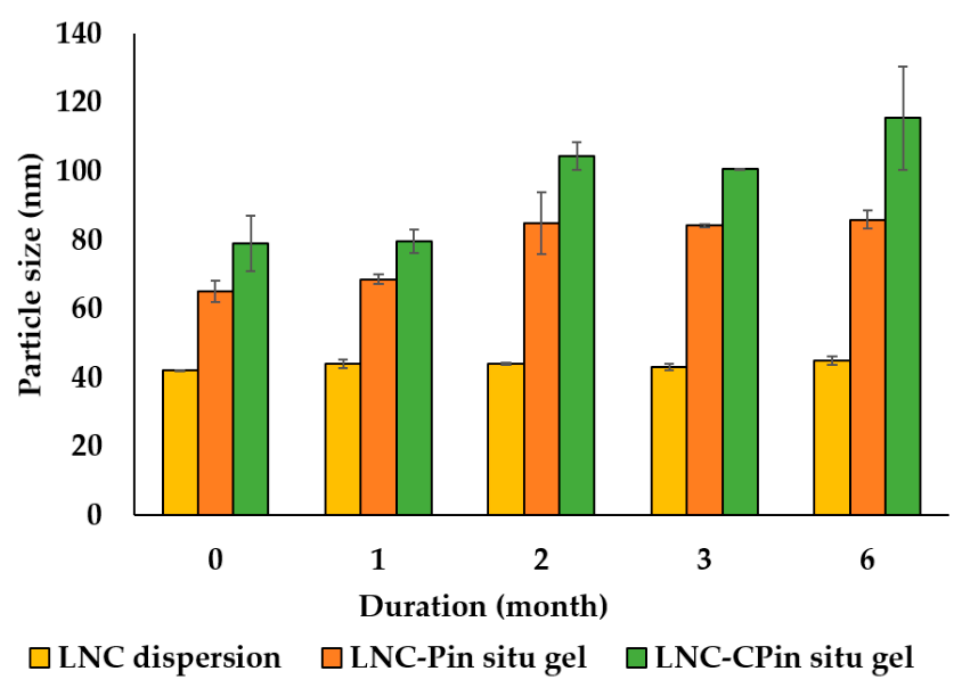

Figure 4. Particle size (nm) of CsA loaded LNC dispersion and in situ gels during storage at $4{ }^{\circ} \mathrm{C}$ over time. $(n=3)$.

PdI followed the same pattern as the particle size; in situ gels remained monodispersed over the storage period with pdI $<0.25(p>0.05)$. $\zeta$-potential data for $L N C-C P_{\text {in situ gel }}$ indicated no significant change over six months $(6.5 \pm 1.0$ and $7.1 \pm 0.6 \mathrm{mV}$ at 0 and six months, respectively). Similarly, \% EE showed no significant change over six months $(p>0.05)$; all formulations remained above $98 \% \mathrm{EE}$.

$\zeta$-potential values beyond $\pm 30 \mathrm{mV}$ are considered required for electrostatic stabilization; systems with values between \pm 5 to $\pm 15 \mathrm{mV}$ are in the limited flocculation region while those between \pm 3 to $\pm 5 \mathrm{mV}$ are likely to flocculate [54]. This rule may not apply to nano-systems such as LNCs with steric stabilizers, where lower $\zeta$ - potential can provide sufficient stabilization [54]. LNCs with low negative $\zeta$-potential stored at $4{ }^{\circ} \mathrm{C}$ were reported stable for over 18 months and those stored at $37^{\circ} \mathrm{C}$ were stable for 1.5 months [16]. 


\subsection{Ex Vivo Results}

Mucoadhesive Force

Data assessing mucoadhesive force at $37^{\circ} \mathrm{C}$, of CsA-loaded LNCs dispersions and LNC in-situ gels expressed as the force required to detach the formulation from the corneal surface [31], were generated using the modified physical balance method [39], the formulation was applied between two face-to-face placed bovine corneas.

LNC dispersion showed lowest mucoadhesive force $\left(338.1 \pm 36.5\right.$ dyne $\left./ \mathrm{cm}^{2}\right)$. Chitosan $(0.5 \% w / v)$ addition to $\mathrm{LNC}_{\text {dispersion }}$ increased mucoadhesive force to $629.4 \pm 146.9$ dyne $/ \mathrm{cm}^{2}$, $(p>0.05)$. Value recorded for LNC-P in situ gel was $2127.5 \pm 377.3$ dyne $/ \mathrm{cm}^{2}(p<0.001$, vs. LNC dispersion), due to increased gel viscosity at the study temperature, and also to the ability of polymers with hydrophilic functional groups such as hydroxyl groups in $\mathrm{P}$ to form electrostatic and hydrophobic interactions as well as hydrogen bonding with cornea surface $[55,56]$.

Addition of chitosan to the in situ gels further increased mucoadhesive force (LNC$\mathrm{CP}_{\text {in situ gel }}, 3412.3 \pm 442 \mathrm{dyne} / \mathrm{cm}^{2}, p<0.001$, vs. $\mathrm{LNC}-\mathrm{P}_{\text {in situ gel, }}$ ) due probably to ionic interaction between chitosan amino group and anionic substructures of cornea mucus layer [57]. The increase in mucoadhesive force observed suggests that both $\mathrm{P}$ and $\mathrm{C}$ are present on the surface of the LNCs.

\subsection{In Vivo Data}

\subsubsection{Corneal Biodistribution}

Confocal microscopy using a fluorescent dye offers an attractive alternative to analyzing drug in cornea layers when faced with the limitation of the analytical method. In the case of CsA, the sensitivity of the HPLC method did not allow assessing CsA levels in the successive cornea layers at $3 \mathrm{~h}$ post instillation in the rabbits.

The choice of Dil as a lipophilic fluorescent dye to act as CsA surrogate was based on results of several published studies providing proof of fluorescent dye labeling stability in lipid nanocapsules when using lipophilic indocarbocyanines (DiO, DiI, and DiD) incorporated in LNCs compared to other fluorescent substances [58,59].

Cornea distribution of fluorescent DiI was observed by confocal laser microscopy (Figure 5). Based on fluorescence intensity (Figure 5A), highest accumulation was achieved by DiI-LNC-CP in situ gel $_{\text {followed by DiI-LNC }}$ dispersion $(p>0.05)$. Values for DiI-Castor oil and control DiI solution were lower. The reported stability of DiI in LNCs [58,59] suggested that the data reflected the biodistribution of LNC entrapping Dil.

A

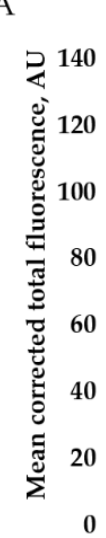

0

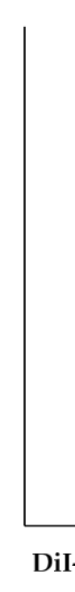

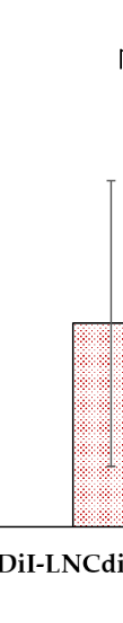
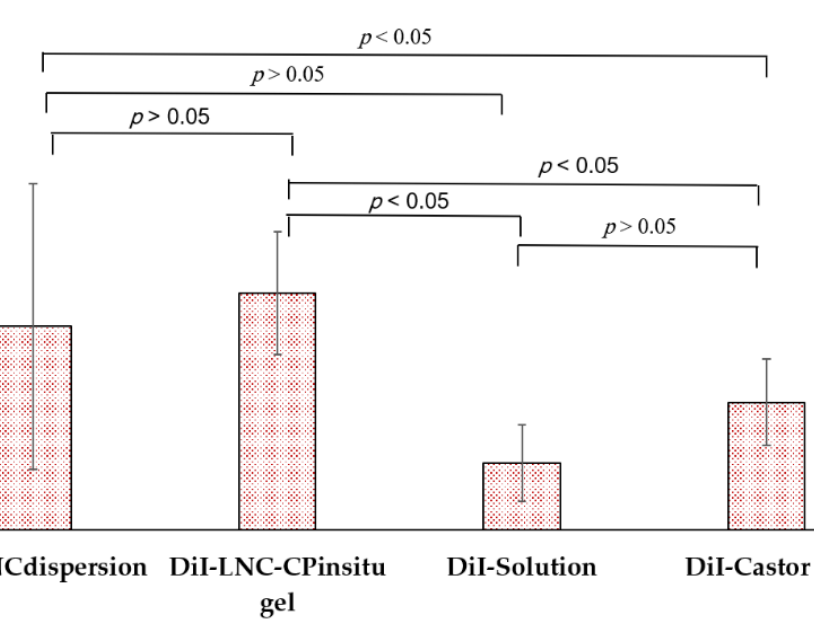

B
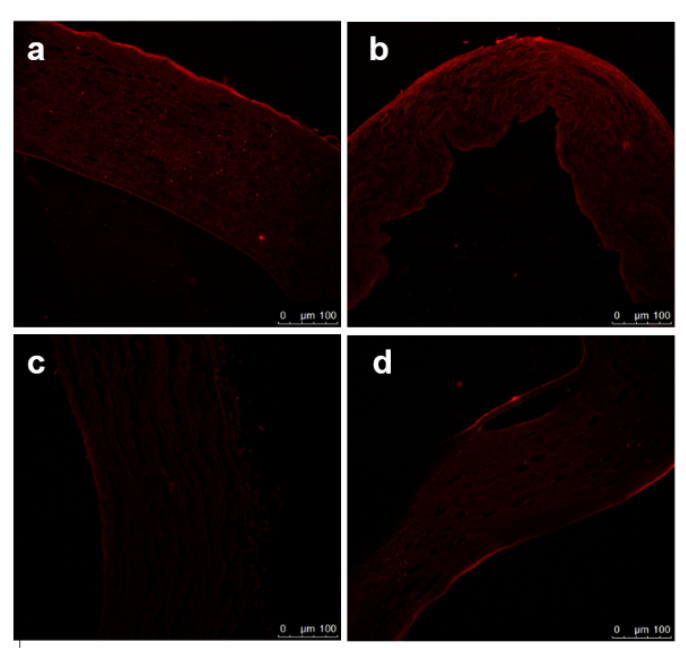

Figure 5. In vivo corneal biodistriution $3 \mathrm{~h}$ post administration showing: (A) Mean corrected total fluorescence of corneas following administration of different DiI formulations and (B) confocal images of cornea layers following administration of

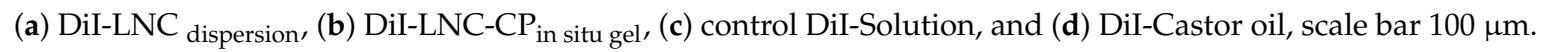


DiI-LNC formulations showed strong fluorescence in cornea layers, with fluorescence in corneal epithelium higher than in stroma (Figure 5B(a,b)). Control DiI solution confocal images (Figure 5B(c)) showed limited fluorescence in corneal layers due, possibly, to the hydrophobic nature of the corneal epithelium. DiI-Castor oil confocal images showed fluorescence in corneal epithelium with limited to no fluorescence in stroma (Figure 5B(d)). Results suggested the presence of LNCs enhanced DiI dye penetration and accumulation in cornea, possibly serving as drug reservoir.

The positive effect of drug encapsulation in LNCs on corneal accumulation could be partly justified by their small particle size $(<50 \mathrm{~nm})$; previous reports have shown that nanocarrier particle size is inversely proportional to membrane permeability with particles below $400 \mathrm{~nm}$ showing greater penetration through polarized epithelial cells [60,61]. The amphiphilic nature of LNCs could probably enable them to permeate through the hydrophobic corneal epithelium and endothelium and to accumulate within the hydrophilic stromal layer [62]. Additionally, the polyoxyethylene-type nonionic surfactant surface displays a P-gp efflux pump inhibitory effect expressed on the surface of corneal epithelial cells, believed to be a major barrier to drug delivery [63].

Corneal accumulation may also be due to infiltration mechanism, where the nanocarrier (polycaprolactone nanospheres) were claimed to be absorbed onto the corneal surface, followed by transport of encapsulated drug into the corneal epithelial cell membrane [64].

\subsubsection{Comparative In Vivo Efficacy in the Dry Eye Rabbit Model}

Schirmer Tear Test (STT) without anesthesia (type I) was used to measure aqueous tear secretion in response to both conjunctival stimulation and basal non-reflex secretion. Dry eye induction model was selected; it is simple and able to rapidly induce dry eye (DE) symptoms compared to other invasive models. Burgalassi et al. [65] reported that decreased tear production can be expected on the second day of topical atropine sulphate (AS) instillation evident by decreased STT values, due to antimuscarinic effect on lacrimal gland's innervations by parasympathetic fibers of the seventh cranial nerve.

Baseline tear production was recorded on day 0 before AS instillation; average tear production was $10.48 \pm 4.3 \mathrm{~mm}, \mathrm{n}=36$ (18 rabbits, both eyes). Differences between the study groups were insignificant $(p<0.4)$. Tear production was then followed over a period of 10 days (Table 2).

Table 2. Schirmer tear test values of rabbits receiving $0.9 \%$ saline only for 10 days (negative control), or $1 \%$ AS for 10 days and either not treated (positive control) or treated starting on day 4 with CsA-NE $(0.05 \%)$, CsA in castor oil ( $0.05 \%)$, or CsA-LNC-CP in situ gel $(0.05$ and $0.1 \%)$.

\begin{tabular}{cccccccc}
\hline \multirow{2}{*}{$\begin{array}{c}\text { Group } \\
\text { Days }\end{array}$} & Saline & AS & $\begin{array}{c}\text { AS/ } \\
\text { CsA-NE }\end{array}$ & $\begin{array}{c}\text { AS/CsA in } \\
\text { Castor Oil }\end{array}$ & $\begin{array}{c}\text { AS/0.05\% CsA- } \\
\text { LNC-CP }\end{array}$ in situ gel & $\begin{array}{c}\text { AS/0.1\% CsA- } \\
\text { LNC-CP }\end{array}$ in situ gel \\
\hline 0 & $10 \pm 1.0$ & $6.8 \pm 1.3$ & $10.3 \pm 1.5$ & $11.0 \pm 4.0$ & $10.3 \pm 2.6$ & $14.4 \pm 6.1$ \\
\hline 3 & $11.3 \pm 3.1$ & $2.2 \pm 0.4$ & $2.0 \pm 1.7$ & $4.3 \pm 2.3$ & $5.5 \pm 2.5$ & $3.8 \pm 0.8$ \\
\hline 5 & $10.3 \pm 3.8$ & $2.8 \pm 1.1$ & $6.0 \pm 3.0$ & $5.0 \pm 1.7$ & $10.5 \pm 4.2$ & $12.4 \pm 4.3$ \\
\hline 7 & $11.7 \pm 3.2$ & $2.8 \pm 1.2$ & $10.7 \pm 3.3$ & $5.8 \pm 0.8$ & $12.0 \pm 2.45$ & $17.1 \pm 4.7$ \\
\hline 10 & $11.7 \pm 3.2$ & $3.1 \pm 0.9$ & $10.2 \pm 3.9$ & $6.7 \pm 3.0$ & $12.2 \pm 2.0$ & $16.0 \pm 3.7$ \\
\hline
\end{tabular}

The negative control group (3 rabbits) receiving normal saline drops maintained a consistent STT value over 10 days $(11 \mathrm{~mm} \pm 2.65)$. A significant reduction in tear production ( $p<0.01$, compared to day 0 values) was recorded for the other five animal groups (15 rabbits) receiving 1\% AS eye drops three times daily, measured on day 3 indicating successful induction of DE, maintained over the study period by three times daily instillation of $1 \%$ AS (maintenance evident in untreated positive control group data, Table 2). 
Starting from day 5 , an increase in STT value was observed for the four treated groups. Compared to day 3 values, changes were statistically insignificant $(p>0.5)$ for both CsA-NE and CsA/castor oil treated groups (values changed from $2.0 \pm 1.7 \mathrm{~mm}$ and $4.3 \pm 2.3 \mathrm{~mm}$ on day 3 to $6.0 \pm 3 \mathrm{~mm}$ and $5.0 \pm 1.7 \mathrm{~mm}$ on day 5 , respectively). $\mathrm{LNC}-\mathrm{CP}_{\text {in situ gels }}$ treated groups showed a statistically significant $(p<0.005)$ increase in STT values which changed from $5.5 \pm 2.5$ and $3.8 \pm 0.8 \mathrm{~mm}$ on day 3 to $10.5 \pm 4.2$ and $12.4 \pm 4.3 \mathrm{~mm}$ on day 5 for $0.05 \%$ and $0.1 \%$ CsA, respectively (Table 2 ).

Figure 6 (data expressed as percent tear production, with reference to day 0 values) allowed judging comparative efficacy. Judging by recovery of baseline tear value, three of the four tested formulations (two LNC formulations and CsA-NE) produced 100\% recovery by day 7; CsA in castor oil failed to bring about complete recovery of base line tear value by day 10 .

(a)

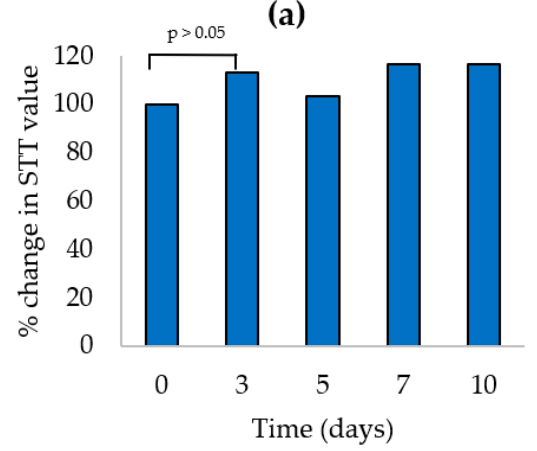

(d)

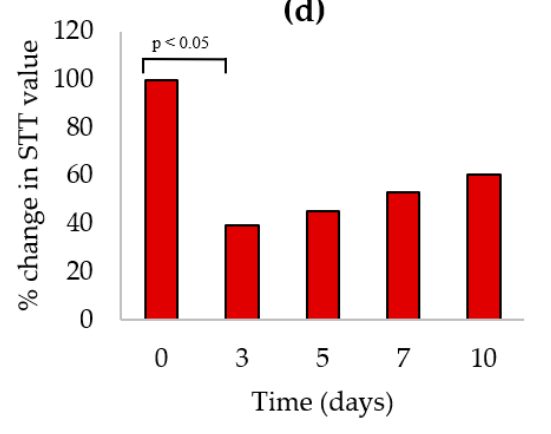

(b)

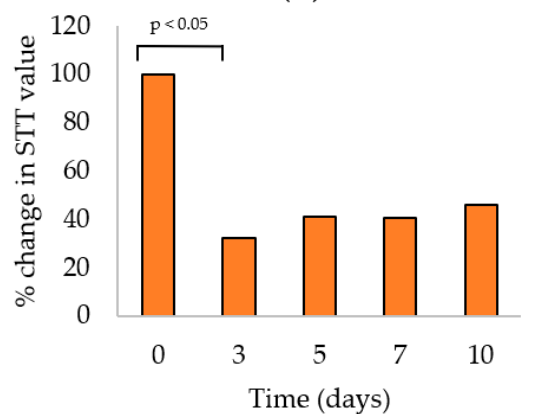

(e)

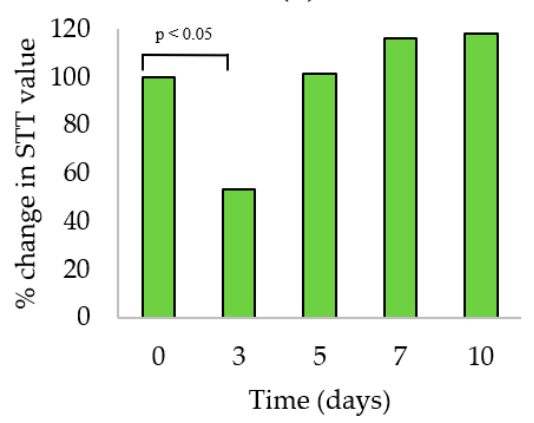

(c)

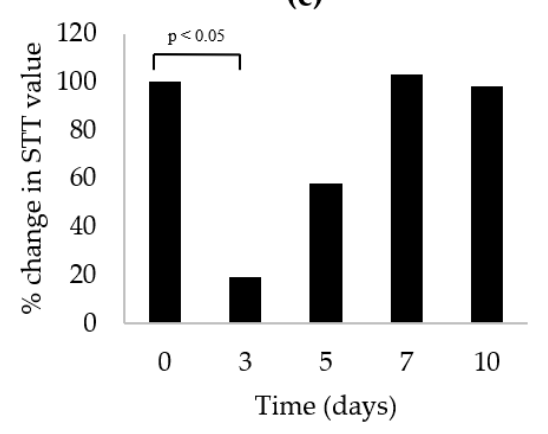

(f)

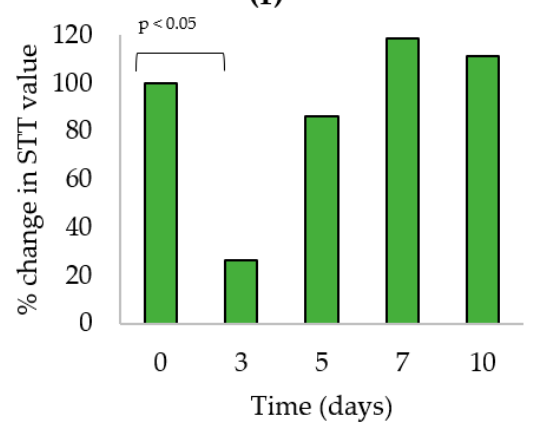

Figure 6. Change in Schirmer tear test values (day 0 values expressed as $100 \%$ ), in rabbits over a 10-day period after daily instillation of (a) $0.9 \%$ saline only, or $1 \%$ AS and either (b) not treated or treated with (c) CsA-NE, (d) CsA in castor oil, (e) CsA-LNC-CP in situ gel $(0.05 \% \mathrm{CsA})$, or (f) CsA-LNC-CP in situ gel $(0.1 \% \mathrm{CsA})$.

Concerning comparative rate of recovery (difference in percent tear production from day 3 to day 5, Figure 6), the values were $60 \%, 48 \%$, and $39 \%$ for $0.1 \%$ CsA-LNC-CP in situ gel, $0.05 \%$ CsA-LNC-CP in situ gel, and CsA-NE, respectively. With CsA in castor oil, the rate of improvement was less than $5 \%$.

In vivo efficacy of $0.05 \%$ and $0.1 \% \mathrm{CsA}-\mathrm{LNC}-\mathrm{CP}_{\text {in situ gel }}$ could be partly attributed to gel mucoadhesive properties enhanced by interaction between positively charged chitosan and negatively charged cornea mucin layer, hence increased CsA-LNC retention on cornea surface.

CsA in castor oil failed to demonstrate comparative therapeutic response in the dry eye rabbit model; it is not clear why baseline tear values were not reached within seven days of initiating treatment. Coating of conjunctiva with residual oil could have prevented proper functioning of the Schirmer tear strip although measurements were taken one hour after instillation of all treatment formulations to allow for partial formulation clearance from conjunctiva. Alternatively, poor tolerance by the eye, rapid clearance from ocular surface $[64,66]$ in addition to poor corneal uptake (demonstrated in the present ex vivo study) could be responsible for the observed lower efficacy of castor oil formulation. 
The Schirmer tear test was able to demonstrate effectiveness of the LNC formulations under the same conditions as the marketed CsA-NE but could not demonstrate greater effectiveness of the $0.1 \%$ compared to the $0.05 \%$ LNC formulation; both gave similar results. The $0.1 \%$ concentration is recommended for severe cases of DE, which may not apply to the dry eye rabbit model.

\subsubsection{Ocular Irritation Test}

Modified Draize test [67] was conducted to assess irritation potential of $0.1 \%$ CsALNC-CP in situ gel in comparison with marketed CsA-NE and CsA/castor oil eye drops.

No behavioral reaction such as eye rubbing was observed in all animals tested following twice daily instillation of any of the three formulations studied. Rabbits showed no symptoms of ocular irritation such as redness, tearing, inflammation, or swelling following twice daily instillation over a period of two weeks. The eye lids showed healthy rosy color with no swelling, and the cornea and conjunctiva showed no pathological alterations in comparison to the control eye receiving only NSS.

To further validate observational results, animals were sacrificed, eyeballs were removed, and histopathological examination of the ocular tissues was done after $\mathrm{H} \& \mathrm{E}$ staining. No signs of changes at cell and tissue levels were detected (Figure 7). Photomicrographs showed no vessel proliferation or immune cell infiltration. The cornea also had an unchanged appearance in all its layers with no angiogenesis or inflammatory signs when compared with published normal bovine cornea photomicrographs [68].

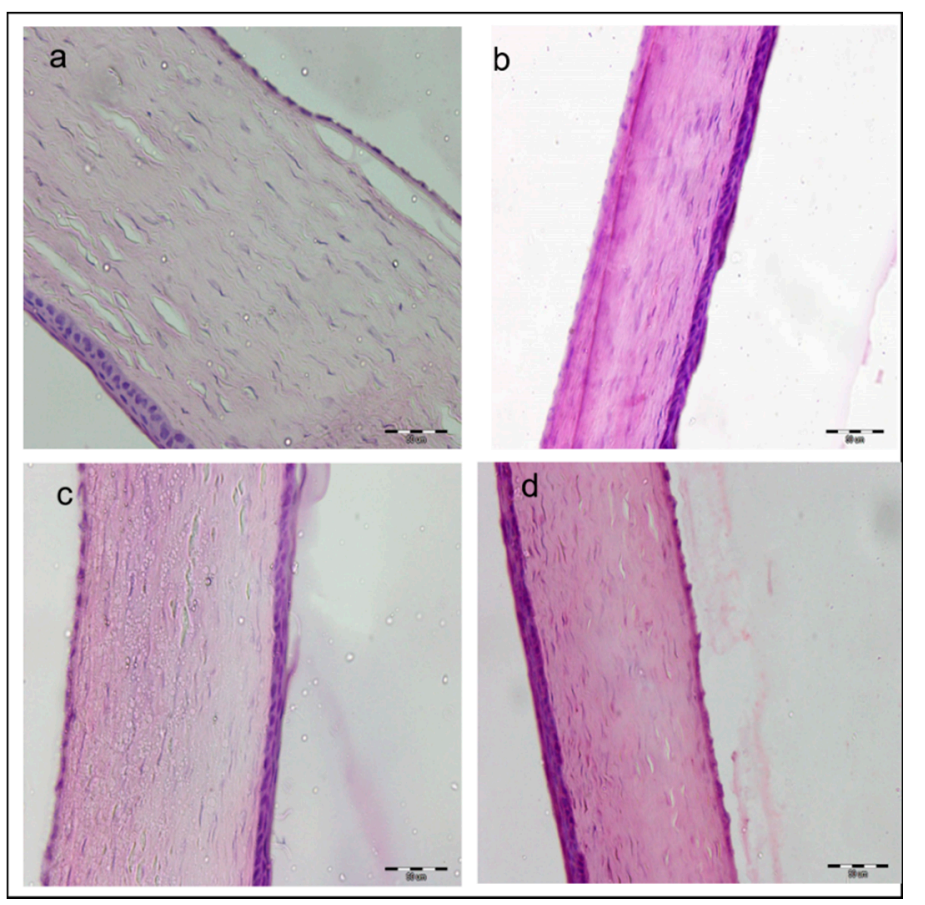

Figure 7. Histopathologic evaluations of rabbit corneas after 14 days of twice daily administration of (a) normal saline, (b) CsA-NE, (c) CsA in castor oil and (d) $0.1 \%$ CsA-LNC-CP in situ gel. scale bar $50 \mu \mathrm{m}$.

\section{Conclusions}

A mucoadhesive thermoresponsive ophthalmic in situ gel containing CsA loaded in LNCs was developed and characterized. In vitro, ex vivo, and in vivo data generated provided evidence that CsA- LNC-CP in situ gel could serve as an effective patient-friendly formulation for the management of dry eye condition. Results of the present study provide incentive for a future clinical study to determine efficacy and tolerability in humans. The inclusion of chitosan in the gel enhanced mucoadhesion and offers a positively charged promising LNC formulation, possibly useful in other applications. 
Supplementary Materials: The following are available online at https: / /www.mdpi.com/1999-4 923/13/3/360/s1, Figure S1. Chromatogram and Calibration curve of CsA by HPLC-UV assay at $210 \mathrm{~nm}$. Figure S2. IR spectra of (a) kolliphor, (b) labrafac and (c) poloxamer 407. Figure S3. IR spectra of physical mixture of (a) kolliphor-poloxamer 407, (b) labrafac-poloxamer 407 and (c) kolliphor-labrafac-poloxamer 407. Figure S4. IR septra of (a) blank LNC and (b) blank LNC in P407 in situ gel.

Author Contributions: Conceptualization, A.A.R.; methodology, R.M.E.-M. and A.A.R.; software, L.M.E.; validation, L.M.E.; formal analysis, L.M.E.; investigation, L.M.E.; resources, L.M.E.; data curation, L.M.E., R.M.E.-M., A.A.R. and N.M.K.; writing-original draft preparation, N.M.K.; writingreview and editing, R.M.E.-M., A.A.R. and N.M.K.; visualization, R.M.E.-M.; supervision, M.H.M. and N.M.K.; project administration, R.M.E.-M. and A.A.R. All authors have read and agreed to the published version of the manuscript.

Funding: This research received no external funding.

Institutional Review Board Statement: The study was conducted according to the ethical guidelines, and approved by the Institutional Ethics Committee of the Faculty of Pharmacy, Alexandria University, Alexandria, Egypt (protocol code AU2020/1/67) and date of approval, 12 January 2020).

Informed Consent Statement: Not applicable.

Acknowledgments: Authors thank Adnan Bekheit of Pharmaceutical Chemistry, Faculty of Pharmacy, Alexandria University for his kind gift of Cyclosporine A powder, for his valuable interpretation of FTIR spectra and for suggesting we collaborate with Mahmoud Morsi of Ophthalmology, Faculty of Medicine, Alexandria University.

Conflicts of Interest: The authors declare no conflict of interest.

\section{References}

1. Ahmed, T.A.; Aljaeid, B.M. A potential in situ gel formulation loaded with novel fabricated poly(lactide-co-glycolide) nanoparticles for enhancing and sustaining the ophthalmic delivery of ketoconazole. Int. J. Nanomed. 2017, 12, 1863-1875. [CrossRef] [PubMed]

2. Willcox, M.D.P.; Argüeso, P.; Georgiev, G.A.; Holopainen, J.M.; Laurie, G.W.; Millar, T.J.; Papas, E.B.; Rolland, J.P.; Schmidt, T.A.; Stahl, U.; et al. TFOS DEWS II Tear Film Report. Ocul. Surf. 2017, 15, 366-403. [CrossRef] [PubMed]

3. Stapleton, F.; Alves, M.; Bunya, V.Y.; Jalbert, I.; Lekhanont, K.; Malet, F.; Na, K.-S.; Schaumberg, D.; Uchino, M.; Vehof, J.; et al. TFOS DEWS II Epidemiology Report. Ocul. Surf. 2017, 15, 334-365. [CrossRef]

4. Javadi, M.-A.; Feizi, S. Dry Eye Syndrome. J. Ophthalmic Vis. Res. 2011, 6, 192-198. [PubMed]

5. Agarwal, P.; Rupenthal, I.D. Modern approaches to the ocular delivery of cyclosporine A. Drug Discov. Today 2016, 21, 977-988. [CrossRef] [PubMed]

6. Lallemand, F.; Felt-Baeyens, O.; Besseghir, K.; Behar-Cohen, F.; Gurny, R. Cyclosporine A delivery to the eye: A pharmaceutical challenge. Eur. J. Pharm. Biopharm. 2003, 56, 307-318. [CrossRef]

7. Luschmann, C.; Tessmar, J.; Schoeberl, S.; Strauss, O.; Framme, C.; Luschmann, K.; Goepferich, A. Developing an in situ nanosuspension: A novel approach towards the efficient administration of poorly soluble drugs at the anterior eye. Eur. J. Pharm. Sci. 2013, 50, 385-392. [CrossRef]

8. Rodriguez-Aller, M.; Guillarme, D.; El Sanharawi, M.; Behar-Cohen, F.; Veuthey, J.-L.; Gurny, R. In vivo distribution and ex vivo permeation of cyclosporine A prodrug aqueous formulations for ocular application. J. Control. Release 2013, 170, 153-159. [CrossRef]

9. De Oliveira, R.C.; Wilson, S.E. Practical guidance for the use of cyclosporine ophthalmic solutions in the management of dry eye disease. Clin. Ophthalmol. 2019, 13, 1115-1122. [CrossRef]

10. Guada, M.; Sebastián, V.; Irusta, S.; Feijoó, E.; Del Carmen Dios-Viéitez, M.; Blanco-Prieto, M.J. Lipid nanoparticles for cyclosporine a administration: Development, characterization, and in vitro evaluation of their immunosuppression activity. Int. J. Nanomed. 2015, 10, 6541.

11. Di Tommaso, C.; Bourges, J.-L.; Valamanesh, F.; Trubitsyn, G.; Torriglia, A.; Jeanny, J.-C.; Behar-Cohen, F.; Gurny, R.; Möller, M. Novel micelle carriers for cyclosporin A topical ocular delivery: In vivo cornea penetration, ocular distribution and efficacy studies. Eur. J. Pharm. Biopharm. 2012, 81, 257-264. [CrossRef]

12. Lallemand, F.; Schmitt, M.; Bourges, J.-L.; Gurny, R.; Benita, S.; Garrigue, J.-S. Cyclosporine A delivery to the eye: A comprehensive review of academic and industrial efforts. Eur. J. Pharm. Biopharm. 2017, 117, 14-28. [CrossRef]

13. Qi, J.; Wu, W.; Wang, K.; Weng, T.; Tian, Z.; Lu, Y.; Hu, K.; Yin, Z. Enhancement of oral bioavailability of cyclosporine A: Comparison of various nanoscale drug-delivery systems. Int. J. Nanomed. 2014, 9, 4991-4999. [CrossRef]

14. Yavuz, B.; Pehlivan, S.B.; Ünlü, N. An Overview on Dry Eye Treatment: Approaches for Cyclosporin A Delivery. Sci. World J. 2012, 2012, 1-11. [CrossRef] 
15. Huynh, N.; Passirani, C.; Saulnier, P.; Benoit, J. Lipid nanocapsules: A new platform for nanomedicine. Int. J. Pharm. 2009, 379, 201-209. [CrossRef]

16. Morille, M.; Montier, T.; Legras, P.; Carmoy, N.; Brodin, P.; Pitard, B.; Benoît, J.-P.; Passirani, C. Long-circulating DNA lipid nanocapsules as new vector for passive tumor targeting. Biomaterials 2010, 31, 321-329. [CrossRef] [PubMed]

17. Heurtault, B.; Saulnier, P.; Pech, B.; Proust, J.; Benoit, J. A Novel Phase Inversion-Based Process for the Preparation of Lipid Nanocarriers. Pharm. Res. 2002, 19, 875-880. [CrossRef] [PubMed]

18. Heurtault, B.; Saulnier, P.; Pech, B.; Venier-Julienne, M.-C.; Proust, J.-E.; Phan-Tan-Luu, R.; Benoît, J.-P. The influence of lipid nanocapsule composition on their size distribution. Eur. J. Pharm. Sci. 2003, 18, 55-61. [CrossRef]

19. Abozaid, D.; Ramadan, A.; Barakat, H.; Khalafallah, N. Acyclovir lipid nanocapsules gel for oromucosal delivery: A preclinical evidence of efficacy in the chicken pouch membrane model. Eur. J. Pharm. Sci. 2018, 121, 228-235. [CrossRef] [PubMed]

20. Lagarce, F.; Alyaa, R.; Pierre, L.; Tessier-Marteau, A.; Thomas, O.; Macchi, L.; Saulnier, P.; Benoit, J.-P.; Ramadan, A.; Legras, P. Oral fondaparinux: Use of lipid nanocapsules as nanocarriers and in vivo pharmacokinetic study. Int. J. Nanomed. 2011, 6, 2941-2951. [CrossRef] [PubMed]

21. Vrignaud, S.; Anton, N.; Gayet, P.; Benoit, J.-P.; Saulnier, P. Reverse micelle-loaded lipid nanocarriers: A novel drug delivery system for the sustained release of doxorubicin hydrochloride. Eur. J. Pharm. Biopharm. 2011, 79, 197-204. [CrossRef] [PubMed]

22. Roger, E.; Lagarce, F.; Garcion, E.; Benoit, J.-P. Lipid nanocarriers improve paclitaxel transport throughout human intestinal epithelial cells by using vesicle-mediated transcytosis. J. Control. Release 2009, 140, 174-181. [CrossRef] [PubMed]

23. Amara, R.O.; Ramadan, A.; El-Moslemany, R.M.; Eissa, M.M.; El-Azzouni, M.Z.; El-Khordagui, L.K. Praziquantel-lipid nanocapsules: An oral nanotherapeutic with potential Schistosoma mansoni tegumental targeting. Int. J. Nanomed. 2018, 13, 4493-4505. [CrossRef]

24. El-Sheridy, N.A.; Ramadan, A.A.; Eid, A.A.; El-Khordagui, L.K. Itraconazole lipid nanocapsules gel for dermatological applications: In vitro characteristics and treatment of induced cutaneous candidiasis. Colloids Surf. B Biointerfaces 2019, 181, 623-631. [CrossRef]

25. Lamprecht, A.; Bouligand, Y.; Benoit, J.-P. New lipid nanocapsules exhibit sustained release properties for amiodarone. J. Control. Release 2002, 84, 59-68. [CrossRef]

26. Formica, M.; Gamboa, G.U.; Tártara, L.; Luna, J.; Benoit, J.; Palma, S. Triamcinolone acetonide-loaded lipid nanocapsules for ophthalmic applications. Int. J. Pharm. 2020, 573, 118795. [CrossRef]

27. Formica, M.L.; Legeay, S.; Bejaud, J.; Montich, G.G.; Gamboa, G.V.U.; Benoit, J.-P.; Palma, S.D. Novel hybrid lipid nanocapsules loaded with a therapeutic monoclonal antibody-Bevacizumab-And Triamcinolone acetonide for combined therapy in neovascular ocular pathologies. Mater. Sci. Eng. C 2021, 119, 111398. [CrossRef] [PubMed]

28. Gupta, H.; Velpandian, T.; Jain, S. Ion-and pH-activated novel in-situ gel system for sustained ocular drug delivery. J. Drug Target. 2010, 18, 499-505. [CrossRef] [PubMed]

29. Ranch, K.; Patel, H.; Chavda, L.; Koli, A.; Maulvi, F.; Parikh, R.K. Development of in situ ophthalmic gel of dexamethasone sodium phosphate and chloramphenicol: A viable alternative to conventional eye drops. J. Appl. Pharm. Sci. 2017, 7, 101-108.

30. Sapino, S.; Chirio, D.; Peira, E.; Rubio, E.A.; Brunella, V.; Jadhav, S.A.; Chindamo, G.; Gallarate, M. Ocular Drug Delivery: A Special Focus on the Thermosensitive Approach. Nanomaterials 2019, 9, 884. [CrossRef] [PubMed]

31. Giuliano, E.; Paolino, D.; Fresta, M.; Cosco, D. Mucosal Applications of Poloxamer 407-Based Hydrogels: An Overview. Pharmaceutics 2018, 10, 159. [CrossRef]

32. Morsi, N.; Ghorab, D.; Refai, H.; Teba, H. Ketoroloac tromethamine loaded nanodispersion incorporated into thermosensitive in situ gel for prolonged ocular delivery. Int. J. Pharm. 2016, 506, 57-67. [CrossRef] [PubMed]

33. Khan, S.; Warade, S.; Singhavi, D.J. Improvement in Ocular Bioavailability and Prolonged Delivery of Tobramycin Sulfate Following Topical Ophthalmic Administration of Drug-Loaded Mucoadhesive Microparticles Incorporated in Thermosensitive in Situ Gel. J. Ocul. Pharmacol. Ther. 2018, 34, 287-297. [CrossRef] [PubMed]

34. Imam, S.S.; Bukhari, S.N.A.; Ahmad, J.; Ali, A. Formulation and optimization of levofloxacin loaded chitosan nanoparticle for ocular delivery: In-vitro characterization, ocular tolerance and antibacterial activity. Int. J. Biol. Macromol. 2018, 108, 650-659. [CrossRef]

35. Al-Kassas, R.; Wen, J.; Cheng, A.E.-M.; Kim, A.M.-J.; Liu, S.S.M.; Yu, J. Transdermal delivery of propranolol hydrochloride through chitosan nanoparticles dispersed in mucoadhesive gel. Carbohydr. Polym. 2016, 153, 176-186. [CrossRef] [PubMed]

36. Fathalla, Z.M.; Vangala, A.; Longman, M.; Khaled, K.A.; Hussein, A.K.; El-Garhy, O.H.; Alany, R.G. Poloxamer-based thermoresponsive ketorolac tromethamine in situ gel preparations: Design, characterisation, toxicity and transcorneal permeation studies. Eur. J. Pharm. Biopharm. 2017, 114, 119-134. [CrossRef]

37. Yang, Z.; Nie, S.; Hsiao, W.L.W.; Pam, W. Thermoreversible Pluronic ${ }^{\circledR}$ F127-based hydrogel containing liposomes for the controlled delivery of paclitaxel: In vitro drug release, cell cytotoxicity, and uptake studies. Int. J. Nanomed. 2011, 6, 151-166. [CrossRef] [PubMed]

38. Varshosaz, J.; Tabbakhian, M.; Salmani, Z. Designing of a Thermosensitive Chitosan/Poloxamer In Situ Gel for Ocular Delivery of Ciprofloxacin. Open Drug Deliv. J. 2008, 2, 61-70. [CrossRef]

39. Gan, L.; Gan, Y.; Zhu, C.; Zhang, X.; Zhu, J. Novel microemulsion in situ electrolyte-triggered gelling system for ophthalmic delivery of lipophilic cyclosporine A: In vitro and in vivo results. Int. J. Pharm. 2009, 365, 143-149. [CrossRef] [PubMed] 
40. Gupta, A.; Garg, S.; Khar, R.K. Measurement of bioadhesive strength of mucoadhesive buccal tablets: Design of an in-vitro assembly. Indian Drugs Bombay 1993, 30, 152.

41. Phan, C.-M.; Walther, H.; Gao, H.; Rossy, J.; Subbaraman, L.N.; Jones, L. Development of an In Vitro Ocular Platform to Test Contact Lenses. J. Vis. Exp. 2016, 2016, 53907. [CrossRef] [PubMed]

42. Bitton, E.; Wittich, W. Influence of eye position on the Schirmer tear test. Contact Lens Anterior Eye 2014, 37, 257-261. [CrossRef] [PubMed]

43. Hwang, S.-J.; Karn, P.R.; Kim, H.D.; Kang, H.; Sun, B.K.; Jin, S.-E. Supercritical fluid-mediated liposomes containing cyclosporin A for the treatment of dry eye syndrome in a rabbit model: Comparative study with the conventional cyclosporin a emulsion. Int. J. Nanomed. 2014, 9, 3791. [CrossRef]

44. Peng, Y.; Yu, Y.; Lin, L.; Liu, X.; Zhang, X.; Wang, P.; Hoffman, P.; Kim, S.Y.; Zhang, F.; Linhardt, R.J. Glycosaminoglycans from bovine eye vitreous humour and interaction with collagen type II. Glycoconj. J. 2018, 35, 119-128. [CrossRef]

45. Hirsjärvi, S.; Dufort, S.; Gravier, J.; Texier, I.; Yan, Q.; Bibette, J.; Sancey, L.; Josserand, V.; Passirani-Malleret, C.; Benoit, J.-P.; et al. Influence of size, surface coating and fine chemical composition on the in vitro reactivity and in vivo biodistribution of lipid nanocapsules versus lipid nanoemulsions in cancer models. Nanomed. Nanotechnol. Biol. Med. 2013, 9, 375-387. [CrossRef] [PubMed]

46. Kim, J.H.; Jang, S.W.; Han, S.D.; Hwang, H.D.; Choi, H.-G. Development of a novel ophthalmic ciclosporin A-loaded nanosuspension using top-down media milling methods. Die Pharm. 2011, 66, 491-495.

47. Zhai, Y.; Yang, X.; Zhao, L.; Wang, Z.; Zhai, G. Lipid nanocapsules for transdermal delivery of ropivacaine: In vitro and in vivo evaluation. Int. J. Pharm. 2014, 471, 103-111. [CrossRef]

48. Lin, H.-R.; Sung, K.C.; Vong, W.-J. In Situ Gelling of Alginate/Pluronic Solutions for Ophthalmic Delivery of Pilocarpine. Biomacromolecules 2004, 5, 2358-2365. [CrossRef]

49. Al Khateb, K.; Ozhmukhametova, E.K.; Mussin, M.N.; Seilkhanov, S.K.; Rakhypbekov, T.K.; Lau, W.M.; Khutoryanskiy, V.V. In situ gelling systems based on Pluronic F127/Pluronic F68 formulations for ocular drug delivery. Int. J. Pharm. 2016, 502, 70-79. [CrossRef]

50. Din, F.U.; Mustapha, O.; Kim, D.W.; Rashid, R.; Park, J.H.; Choi, J.Y.; Ku, S.K.; Yong, C.S.; Kim, J.O.; Choi, H.-G. Novel dual-reverse thermosensitive solid lipid nanoparticle-loaded hydrogel for rectal administration of flurbiprofen with improved bioavailability and reduced initial burst effect. Eur. J. Pharm. Biopharm. 2015, 94, 64-72. [CrossRef]

51. Hao, J.; Wang, X.; Bi, Y.; Teng, Y.; Wang, J.; Li, F.; Li, Q.; Zhang, J.; Guo, F.; Liu, J. Fabrication of a composite system combining solid lipid nanoparticles and thermosensitive hydrogel for challenging ophthalmic drug delivery. Colloids Surf. B Biointerfaces 2014, 114, 111-120. [CrossRef] [PubMed]

52. Almeida, H.; Amaral, M.H.; Lobão, P.; Lobo, J.M.S. In situ gelling systems: A strategy to improve the bioavailability of ophthalmic pharmaceutical formulations. Drug Discov. Today 2014, 19, 400-412. [CrossRef] [PubMed]

53. Desai, S.D.; Blanchard, J. Pluronic ${ }^{\circledR}$ F127-based ocular delivery system containing biodegradable polyisobutylcyanoacrylate nanocapsules of pilocarpine. Drug Deliv. 2000, 7, 201-207.

54. Heurtault, B.; Saulnier, P.; Pech, B.; Proust, J.-E.; Benoit, J.-P. Physico-chemical stability of colloidal lipid particles. Biomaterials 2003, 24, 4283-4300. [CrossRef]

55. Morsi, N.; Ibrahim, M.; Refai, H.; El Sorogy, H. Nanoemulsion-based electrolyte triggered in situ gel for ocular delivery of acetazolamide. Eur. J. Pharm. Sci. 2017, 104, 302-314. [CrossRef]

56. Qi, H.; Chen, W.; Huang, C.; Li, L.; Chen, C.; Li, W.; Wu, C. Development of a poloxamer analogs/carbopol-based in situ gelling and mucoadhesive ophthalmic delivery system for puerarin. Int. J. Pharm. 2007, 337, 178-187. [CrossRef]

57. Şenyiğit, Z.A.; Karavana, S.Y.; Ozdemir, D.I.; Caliskan, C.; Waldner, C.; Sen, S.; Bernkop-Schnürch, A.; Baloglu, E. Design and evaluation of an intravesical delivery system for superficial bladder cancer: Preparation of gemcitabine HCl-loaded chitosanthioglycolic acid nanoparticles and comparison of chitosan/poloxamer gels as carriers. Int. J. Nanomed. 2015, 10, $6493-6507$. [CrossRef] [PubMed]

58. Bastiat, G.; Pritz, C.O.; Roider, C.; Fouchet, F.; Lignières, E.; Jesacher, A.; Glueckert, R.; Ritsch-Marte, M.; Schrott-Fischer, A.; Saulnier, P.; et al. A new tool to ensure the fluorescent dye labeling stability of nanocarriers: A real challenge for fluorescence imaging. J. Control. Release 2013, 170, 334-342. [CrossRef]

59. Simonsson, C.; Bastiat, G.; Pitorre, M.; Klymchenko, A.S.; Bejaud, J.; Mely, Y.; Benoit, J.-P. Inter-nanocarrier and nanocarrier-to-cell transfer assays demonstrate the risk of an immediate unloading of dye from labeled lipid nanocapsules. Eur. J. Pharm. Biopharm. 2016, 98, 47-56. [CrossRef]

60. Ban, J.; Zhang, Y.; Huang, X.; Deng, G.; Hou, D.; Chen, Y.; Lu, Z. Corneal permeation properties of a charged lipid nanoparticle carrier containing dexamethasone. Int. J. Nanomed. 2017, 12, 1329-1339. [CrossRef]

61. Wagh, V.D.; Apar, D.U. Cyclosporine A Loaded PLGA Nanoparticles for Dry Eye Disease:In VitroCharacterization Studies. J. Nanotechnol. 2014, 2014, 1-10. [CrossRef]

62. Chen, Y.; Lu, Y.; Zhong, Y.; Wang, Q.; Wu, W.; Gao, S. Ocular delivery of cyclosporine A based on glyceryl monooleate/poloxamer 407 liquid crystalline nanoparticles: Preparation, characterization, in vitrocorneal penetration and ocular irritation. J. Drug Target. 2012, 20, 856-863. [CrossRef] 
63. Dey, S.; Patel, J.; Anand, B.S.; Jain-Vakkalagadda, B.; Kaliki, P.; Pal, D.; Ganapathy, V.; Mitra, A.K. Molecular evidence and functional expression of P-glycoprotein (MDR1) in human and rabbit cornea and corneal epithelial cell lines. Investig. Opthalmology Vis. Sci. 2003, 44, 2909-2918. [CrossRef] [PubMed]

64. Yenice, I.; Mocan, M.C.; Palaska, E.; Bochot, A.; Bilensoy, E.; Vural, I.; Irkec, M.; Hincal, A.A.; Hincal, A.A. Hyaluronic acid coated

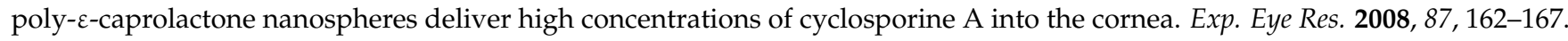
[CrossRef] [PubMed]

65. Burgalassi, S.; Panichi, L.; Chetoni, P.; Saettone, M.F.; Boldrini, E. Development of a simple dry eye model in the albino rabbit and evaluation of some tear substitutes. Ophthalmic Res. 1999, 31, 229-235. [CrossRef]

66. Luschmann, C.; Herrmann, W.; Strauß, O.; Luschmann, K.; Goepferich, A. Ocular delivery systems for poorly soluble drugs: An in-vivo evaluation. Int. J. Pharm. 2013, 455, 331-337. [CrossRef] [PubMed]

67. Li, N.; Zhuang, C.; Wang, M.; Sun, X.; Nie, S.; Pan, W. Liposome coated with low molecular weight chitosan and its potential use in ocular drug delivery. Int. J. Pharm. 2009, 379, 131-138. [CrossRef] [PubMed]

68. Institute for in Vitro Sciences. Guidelines for Histopathological Evaluation of Bovine Corneas as an Endpoint of the Bovine Corneal Opacity and Permeability (Bcop) Assay; OECD: Maryland, MD, USA, 2016. 